\title{
EVALUASI UNJUK KERJA REAKTOR ALIR TANGKI BERPENGADUK MENGGUNAKAN PERUNUT RADIOISOTOP
}

\author{
NOOR ANIS KUNDARI, DJOKO MARJANTO, ARDHANI DYAH W \\ Sekolah Tinggi Teknologi Nuklir, BATAN Yogyakarta \\ Jl.Babarsari Kotak Pos 6101/YKBB Yogyakarta 55281 \\ Telp. 0274.489716 Faks 489715
}

\begin{abstract}
Abstrak
EVALUASI UNJUK KERJA REAKTOR ALIR TANGKI BERPENGADUK MENGGUNAKAN PERUNUT RADIOISOTOP. Penelitian evaluasi unjuk kerja reaktor alir tangki berpengaduk (RATB) menggunakan perunut radioisotop telah dilakukan. Penelitian ini dimaksudkan untuk mengkaji kebenaran penganggapan bahwa pengadukan atau pencampuran dalam reaktor alir tangki berpengaduk adalah sempurna. Untuk dapat menyelidiki dinamika proses aliran fluida dalam reaktor digunakan radioisotop I-131. Fluida/air yang keluar dari reaktor dicuplik pada waktu 13 detik sampai dengan 1373 detik dan dianlisis kadar I-131nya. Unjuk kerja reaktor alir tangki berpengaduk dinyatakan dalam bilangan dispersi (D/uL) dan mengikuti model dispersi aksial sebagai fungsi waktu tinggal rata-rata dan bilangan Reynold. Hasil penelitian menunjukkan bahwa $\mathrm{D} / \mathrm{uL}=9 \mathrm{X} 10^{-4}\left(\mathrm{t}_{\mathrm{s}}{ }^{*}\right)^{2}-6,9 \times 10^{-1}\left(\mathrm{t}_{\mathrm{s}}{ }^{*}\right)+148$ dan $\mathrm{D} / \mathrm{uL}=65,7 \mathrm{e}^{0,0003 / \mathrm{Re}}$. Nilai bilangan dispersi berkisar antara 11,08 sampai 21,4 , selalu jauh di atas 0,01 ini berarti pencampuran yang terjadi dalam reaktor alir berpengaduk yang dievaluasi dapat dianggap ideal.
\end{abstract}

Kata kunci: Bilangan dispersi, unjuk kerja reaktor, perunut, radioisotop

\begin{abstract}
EVALUATION OF CONTINUOUS STIRRED TANK REACTOR PERFORMANCE BY USING RADIOISOTOPE TRACER. Research on performance evaluation of continuous stirred tank reactor (CSTR) using radioisotop tracer has been carried out. The aim of research is to assess a validity of assumption that stirring or mixing process in a CSTR is perfect. In order to follow the flow dynamics process of the fluid in the reactor, I-131 was used. The reactor was equipped with four baffles. The fluid/water leaving the reactor was sampled at 13 up to 1393 seconds and analysed its I-131 concentration. The performance of CSTR is expressed as dispersed number $(\mathrm{D} / \mathrm{uL})$ as function of retention time and Reynold number under axial dispersed model. The experimental result show that the relation between the dispertion number and retention time is $\mathrm{D} / \mathrm{uL}=9 \times 10^{-4}\left(\mathrm{t}_{\mathrm{s}}{ }^{*}\right)^{2}-6.9 \times 10$ ${ }^{1}\left(t_{s}{ }^{*}\right)+148$ and the dispertion number and Reynold number is $\mathrm{D} / \mathrm{uL}=65.7 \mathrm{e}^{0.0003 / \mathrm{Re}}$. The dispersion number obtained were much higher than 0.01 that in between 11.08 up to 21.4. That mean the mixing process occurred in the CSTR can be assumed to be ideal.
\end{abstract}


Keywords: Dispersion Number, Reactor's performance, tracer, radioisotope

\section{PENDAHULUAN}

Pendekatan teoritis pada perancangan reaktor kimia telah dikembangkan secara sistematik dengan mengedepankan seluruh pengetahuan dalam ilmu dasar dan teknik dalam bidang reaksi kimia ${ }^{[1]}$ Pada dasarnya, unjuk kerja reaktor yang sesungguhnya perlu diketahui dan dibandingkan dengan pendekatan teoritis yang telah dikembangkan, termasuk reaktor alir tangki berpengaduk (RATB). Bagian utama reaktor alir tangki berpengaduk adalah tangki dan pengaduk. Pada umumnya reaktor ini dilengkapi dengan saluran masuk dan keluar, penghalang, dan perlengkapan lain sesuai dengan peruntukannya misalnya tutup, termometer, dan pemanas/pendingin ${ }^{[2]}$.

Pada perhitungan-perhitungan yang terkait dengan penggunaan reaktor alir kimia dalam industri, umumnya didekati dengan keadaan ideal. Dalam reaktor alir tangki berpengaduk keadaan ideal berari waktu tinggal setiap komponen di dalam reaktor itu adalah sama serta komposisi yang ke luar dari reaktor sama dengan komposisi di dalam reaktor ${ }^{[3]}$. Informasi ini sudah biasa digunakan untuk menghitung kecepatan reaksi, konversi, ukuran reaktor, keperluan pemanas/pendingin, dan keperluan terkait lainnya. Namun sesungguhnya, yang terjadi dalam reaktor belum tentu ideal. Ketidakidealan ini dapat mengakibatkan kesalahan hasil perhitungan, yang bisa berdampak buruk. Oleh karena itu, perlu dilakukan evaluasi unjuk kerja terhadap reaktor. Evaluasi unjuk kerja RATB dapat dilakukan dengan menganalisis waktu tinggal zat alir di dalam reaktor untuk menentukan bilangan dispersi.

Distribusi waktu tinggal zat cair di dalam RATB dapat ditentukan dengan teknik perunut. Sulistyo dan Handayani, 1997, telah melakukan penelitian Unjuk Kerja Reaktor Alir Tangki Berpengaduk menggunakan perunut $\mathrm{HCl}$. Dari penelitian itu diketahui bahwa unjuk kerja reaktor alir tangki berpengaduk dapat dievaluasi berdasarkan distribusi waktu tinggal perunut $\mathrm{HCl}$ di dalam reaktor ${ }^{[4]}$.

Penelitian ini bertujuan untuk melakukan evaluasi unjuk kerja reaktor alir tangki berpengaduk dengan perunut radioaktif atau perunut radioisotop. Perunut radioaktif yang juga disebut senyawa bertanda, adalah senyawa yang mengandung radioisotop. Penjejak ini dapat digunakan untuk mengukur kecepatan proses kimia, waktu tinggal fluida di dalam reaktor, dan mengikuti gerakan suatu benda dalam sistem hayati seperti sel dan jaringan. Sebelum perunut radioisotop dikenal, seringkali digunakan zat warna atau gugusgugus atom tertentu yang dapat digabungkan dengan molekul senyawa yang hendak diikuti sebagai perunut. Walaupun perunut ini dapat mengikuti proses 
yang bergerak, namun terdapat kekurangan yaitu: 1) bahwa perunut tersebut tidak dapat dipastikan betul-betul mengikuti jalan yang sama dengan bahan yang diikuti akibat perbedaan senyawa; 2) Agar mudah dideteksi, seringkali diperlukan jumlah perunut yang banyak. Dengan perunut radioisotop, kedua kekurangan ini dapat terhapus ${ }^{[5]}$.

Penggunaan isotop radioaktif sebagai perunut didasarkan pada senyawa bertanda dalam jumlah tertentu dimasukkan ke dalam sistem yang akan diselidiki, sehingga dapat bercampur dengan baik. Gerakan radioisotop yang berada dalam sistem itu dapat diikuti dengan detektor sehingga keadaannya dapat dengan mudah diketahui. Hal ini dimungkinkan bila radioisotop itu memancarkan radiasi gamma $(\gamma)$ yang mampu menembus dinding wadah, sehingga dapat dideteksi dari luar tanpa mengganggu keadaan sistem tersebut ${ }^{[6]}$.

Banyak penelitian penggunaan perunut radioaktif yang telah dilakukan. Baba (1985) menggunakan senyawa bertanda C-14 untuk menentukan puncak-puncak dalam analisis kromatografi gas $^{[7]}$. Fuman (2004) menggunakan radioisotop $\mathrm{Cu}-64$ untuk menyelidiki model penurunan kadar air pada pembuatan konsentrat tembaga. Dia melakukan analisis terhadap waktu tinggal rata-rata untuk menentukan model kinetika proses di dalamnya ${ }^{[8]}$.

Secara sederhana, waktu tinggal dalam reaktor alir tangki berpengaduk pada keadaan steady adalah volume tangki terisi cairan dibagi dengan kecepatan alir umpan yang masuk sehingga dapat ditulis dengan persamaan sebagai berikut ${ }^{[9]}$.

$$
\tau=\frac{\mathrm{V}}{\mathrm{F}}
$$

Namun, kondisi yang sesungguhnya terjadi dalam reaktor kimia tidak selalu mencapai keadaan steady terus menerus. Oleh karena itu, jika digunakan Persamaan 1, dapat terjadi penyimpangan.

Tujuan dan prinsip teknik perunut adalah mempelajari dan menyelidiki dinamika suatu sistem dengan cara menandai sistem itu dengan perunut. Suatu bahan dapat digunakan sebagai perunut jika memiliki kriteria: dapat menyatu atau menjadi bagian dari sistem tersebut dan kehadirannya tidak boleh mengganggu, mengubah, dan atau mempengaruhi sistem, serta mudah dideteksi baik secara langsung (in situ) maupun secara pengambilan sampel. Penelitian ini bertujuan untuk mengevaluasi unjuk kerja reaktor alir berpengaduk skala laboratorium dengan perunut radioisotop I-131 karena memiliki kriteria itu ${ }^{[10]}$. 
Penggunaan perunut untuk menentukan distribusi waktu tinggal dinamakan teknik stimulus response, yaitu suatu teknik dengan menambahkan perunut ke dalam aliran masuk reaktor dan menganalisis konsentrasi perunut dalam aliran yang ke luar dari reaktor.

Cara yang lazim dalam menambahkan perunut ke dalam aliran dapat dilakukan dengan cara pulse input ataupun step input. Pada penelitian ini digunakan cara pulse input, yaitu dengan menyuntikkan perunut secara cepat ke dalam reaktor dengan waktu sesingkat mungkin, kemudian konsentrasi perunut yang ke luar dari reaktor di analisis setiap saat.

Evaluasi konsentrasi perunut pada aliran keluar dapat dinyatakan dalam parameter $\mathrm{E}(\mathrm{t})$. Pada penambahan perunut secara pulse input digunakan persamaan sebagai berikut ${ }^{[3]}$.

$$
\begin{aligned}
& E(t)=c(t) / C_{o} \\
& C_{0}=\int_{0}^{\infty} c(t) d t
\end{aligned}
$$

dengan $\mathrm{E}(\mathrm{t})=$ fungsi distribusi waktu tinggal, $\mathrm{c}(\mathrm{t})=$ konsentrasi perunut keluar reaktor setiap saat, dan $\mathrm{C}_{0}=$ jumlah konsentrasi perunut keseluruhan yang masuk ke reaktor.

Berdasarkan fungsi distribusi waktu tinggal, waktu tinggal rata-rata dapat dinyatakan dengan persamaan ${ }^{[3]}$ :

$$
\mathrm{t}^{*}=\int \mathrm{tE}(\mathrm{t}) \mathrm{dt}
$$

dengan $\mathrm{t}^{*}=$ waktu tinggal rata-rata, $\mathrm{t}=$ waktu.

Evaluasi unjuk kerja reaktor dapat dinyatakan dengan model yang didasarkan atas penyimpangan dari keadaan ideal yaitu model dispersi aksial. Pada model dispersi aksial, dianggap bahwa perpindahan massa ke arah aksial terjadi disebabkan oleh difusi dan dibawa aliran yang dinyatakan dengan bilangan dispersi $\mathrm{D} / \mathrm{uL}$, dengan $\mathrm{D}=$ Difusivitas atau kecepatan penyebaran [luas/waktu], u=kecepatan linier fluida [jarak/waktu], dan $\mathrm{L}=$ panjang lintasan. Bilangan dispersi D/uL, merupakan kelompok tak berdimensi yang mencirikan penyebaran fluida secara menyeluruh di dalam tangki. Bilangan dispersi juga menggambarkan proses penyebaran perunut yang dimasukkan ke dalam reaktor, yang dapat dijelaskan sebagai berikut. Nilai D/uL yang besar berarti terjadi penyebaran secara cepat, nilai $\mathrm{D} / \mathrm{uL}$ yang kecil menunjukkan penyebaran yang lambat atau kecil, dan $\mathrm{D}=0$ berarti tidak ada penyebaran. 
Bilangan dispersi dapat ditentukan dengan merekam bentuk kurva konsentrasi perunut yang keluar. Analisis dilakukan dengan menghitung waktu tinggal rata-rata $\left(t^{*}\right)$ dan ukuran penyebaran distribusi atau varian $\left(\sigma^{2}\right)$. Perhitungan $\left(t^{*}\right)$ dan $\left(\sigma^{2}\right)$ untuk data terpisah maupun berkelanjutan dapat menggunakan persamaan sebagai berikut ${ }^{[3]}$.

$$
\begin{aligned}
& \mathrm{t}^{*}=\frac{\int_{0}^{\infty} \mathrm{t} \times \mathrm{c}(\mathrm{t}) \mathrm{dt}}{\int \mathrm{c}(\mathrm{t}) \mathrm{dt}}=\frac{\sum \mathrm{t}_{\mathrm{i}} \mathrm{c}_{\mathrm{i}} \Delta \mathrm{t}_{\mathrm{i}}}{\sum \mathrm{c}_{\mathrm{i}} \Delta \mathrm{t}_{\mathrm{i}}} \\
& \sigma^{2}=\frac{\int_{0}^{\infty}\left(\mathrm{t}-\mathrm{t}^{*}\right) \mathrm{c}(\mathrm{t}) \mathrm{dt}}{\int_{0}^{\infty} \mathrm{c}(\mathrm{t}) \mathrm{dt}}=\frac{\int_{0}^{\infty} \mathrm{t}^{2} \mathrm{c}(\mathrm{t}) \mathrm{dt}}{\int_{0}^{\infty} \mathrm{c}(\mathrm{t}) \mathrm{dt}}-\mathrm{t}^{* 2} \\
& \sigma^{2} \equiv \frac{\sum\left(\mathrm{t}_{\mathrm{i}}-\mathrm{t}^{*}\right)^{2} \mathrm{c}_{\mathrm{i}} \Delta \mathrm{t}_{\mathrm{i}}}{\sum \mathrm{c}_{\mathrm{i}} \Delta \mathrm{t}_{\mathrm{i}}}=\frac{\sum \mathrm{t}_{\mathrm{i}}{ }^{2} \mathrm{c}_{\mathrm{i}} \Delta \mathrm{t}_{\mathrm{i}}}{\sum \mathrm{c}_{\mathrm{i}} \Delta \mathrm{t}_{\mathrm{i}}}-\mathrm{t}^{* 2}
\end{aligned}
$$

Penyusunan neraca massa perunut dalam reaktor menghasilkan persamaan sebagai berikut $^{[3]}$.

$$
\frac{\mathrm{D}}{\mathrm{uL}} \frac{\partial^{2} \mathrm{C}}{\partial \mathrm{z}^{2}}-\frac{\partial \mathrm{C}}{\partial \mathrm{z}}=\frac{\partial \mathrm{C}}{\partial \mathrm{t}}
$$

dengan $\frac{\mathrm{D}}{\mathrm{uL}}$ adalah bilangan dispersi.

Keadaan batas untuk persamaan neraca massa di atas adalah: pada $\mathrm{z}>0$ dan $\mathrm{t}$ $=0, \mathrm{C}=0$ dan pada $\mathrm{z}<0$ dan pada $\mathrm{t}=0, \mathrm{C}=\mathrm{C}_{0}$.

Bilangan dispersi adalah parameter yang menunjukkan luas dispersi atau penyebaran ke arah aksial. Dengan demikian jika $\frac{\mathrm{D}}{\mathrm{uL}}=0$ berarti tidak ada penyebaran, sedangkan jika $\frac{\mathrm{D}}{\mathrm{uL}}=\infty$ berarti terjadi penyebaran secara sempurna. Penyebaran ini juda dapat diartikan pencampuran. Bilangan dispersi dapat ditentukan dengan persamaan ${ }^{[3]}$ : 


$$
\sigma^{2} \theta=2\left(\frac{\mathrm{D}}{\mathrm{uL}}\right)-2\left(\frac{\mathrm{D}}{\mathrm{uL}}\right)^{2}\left[1-\mathrm{e}^{-\mathrm{uL} / \mathrm{D}}\right]
$$

dengan $\sigma^{2} \theta$ adalah varian dalam bentuk tak berdimensi.

Dalam penelitian ini digunakan reaktor dengan dimensi yang ideal yaitu perbandingan ukuran reaktor dan ukuran perlengkapan reaktor serta posisi perlengkapan reaktor dan volume fluida. ${ }^{[2]}$ Dengan demikikian diharapkan akan diperoleh Bilangan Dispersi di atas 0,01. Jika kesalahan kurang dari 5\%, maka penggunaan perunut radioisotop dapat diterima ${ }^{[3]}$.

Agar diperoleh persamaan yang dapat dipergunakan lebih luas, kecepatan pengaduk diubah menjadi Bilangan Reynold. Bilangan Reynold, Re, dapat ditulis dengan sebagai berikut ${ }^{[9]}$.

$$
\operatorname{Re}=\frac{\rho v d}{\mu}
$$

dengan $\rho$ menunjukkan rapat cairan, $v$ adalah kecepatan, $d$ adalah lebar pengaduk, dan $\mu$ adalah viskositas cairan. Kecepatan $v$, adalah kecepatan linier, karena yang diukur dalam penelitian ini adalah kecepatan putar pengaduk, v dapat ditulis dengan kecepatan putar pengaduk dikalikan dengan lebar pengaduk, Nd, sehingga Persamaan 10 dapat ditulis menjadi:

$$
\operatorname{Re}=\frac{\rho N d^{2}}{\mu}
$$

Dari perhitungan waktu tinggal rata-rata, bilangan Reynold, dan nilai D/ul, serta berdasarkan data percobaan maka dapatlah dibuat hubungan D/ul dengan waktu tinggal dan dengan Bilangan Reynold.

\section{METODE PENELITIAN}

\section{Bahan}

Bahan yang digunakan dalam penelitian ini adalah air sebagai fluida yang akan dirunut. Air yang digunakan berasal dari air sumur pada suhu $29^{\circ} \mathrm{C}$, rapat massa $0,996 \mathrm{~g} / \mathrm{mL}$ dan viskositas $0,0082 \mathrm{~g} / \mathrm{cm}$. detik. Radioisotop I-131 dengan waktu setengah umur 8,08 hari, konsentrasi $91 \mathrm{mCi} / \mathrm{mL}$ dan aktivitas awal 18,2 $\mathrm{mCi} / 0,2 \mathrm{~mL}$, diencerkan menjadi 1,5 $\mathrm{mL}$ dengan menambahkan air. 


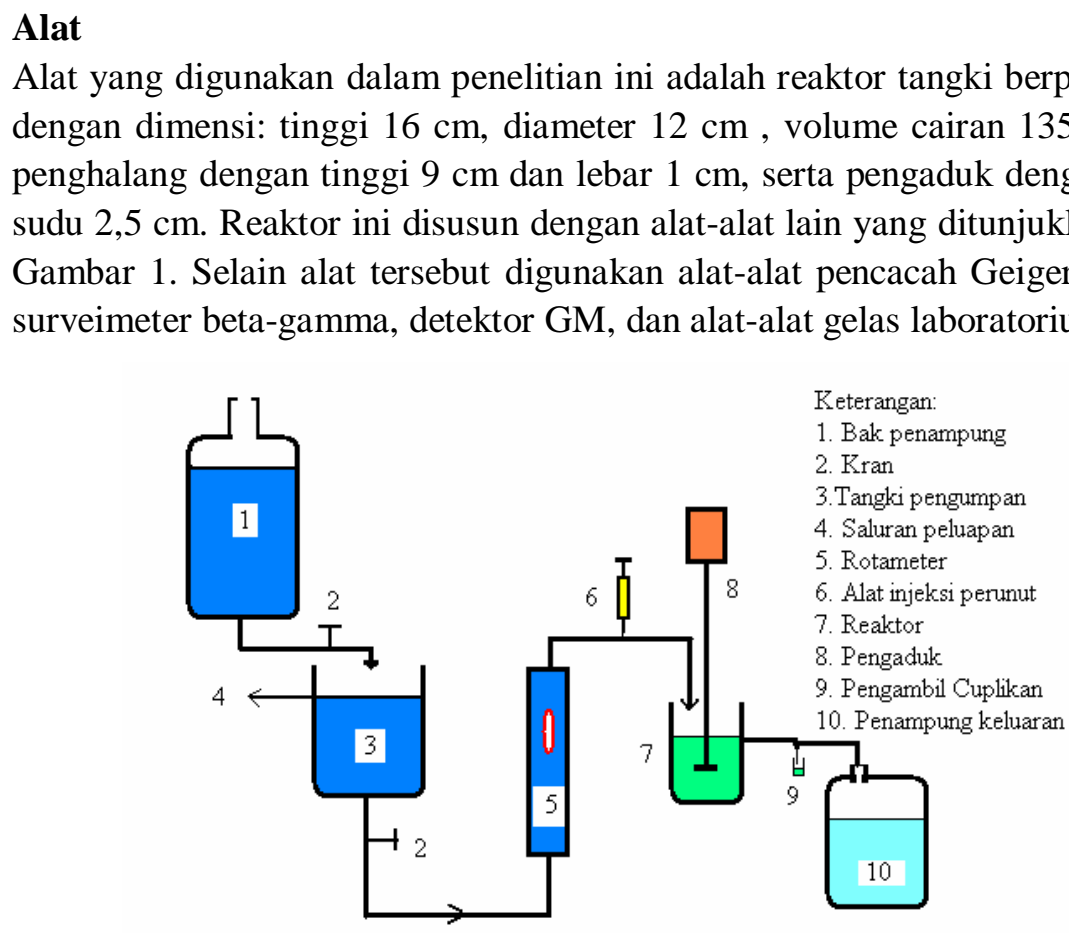

Gambar 1. Rangkaian Alat Percobaan

\section{Cara Kerja}

Mula-mula tangki penampung diisi air sampai penuh kran dibuka sampai terjadi peluapan melalui saluran, kemudian air dialirkan ke dalam reaktor yang sudah berisi air dan diaduk dengan kecepatan putar tertentu. Kecepatan alir diatur, dan dibaca dengan alat rotameter. Setelah keadaan steady, yang ditandai dengan tinggi pelampung yang sudah tetap, $1 \mathrm{~mL}$ perunut diinjeksikan ke dalam aliran umpan. Cuplikan diambil dari aliran yang keluar reaktor, pada beberapa periode waktu dan dimasukkan ke dalam botol plastik, untuk dianalisis kadar perunut dengan teknik pencacahan.

\section{HASIL DAN PEMBAHASAN}

Percobaan dilakukan dengan volume cairan dalam reaktor $1500 \mathrm{~mL}$, variasi kecepatan alir, 0,97, 2,14, dan 3,18 mL/detik dan variasi kecepatan putar pengaduk 125, 150, dan 175 putaran per menit. Perunut yang digunakan adalah I-131 yang memiliki waktu paruh 8,08 hari, dengan aktivitas 0,519 sebanyak 0,2 mL lalu diencerkan menjadi 1,5 mL. Cuplikan air yang keluar 
dari reaktor diambil mulai 13 detik sampai 1393 detik. Hasil percobaan masing-masing dapat dilihat pada Gambar 2 dan Gambar 3.

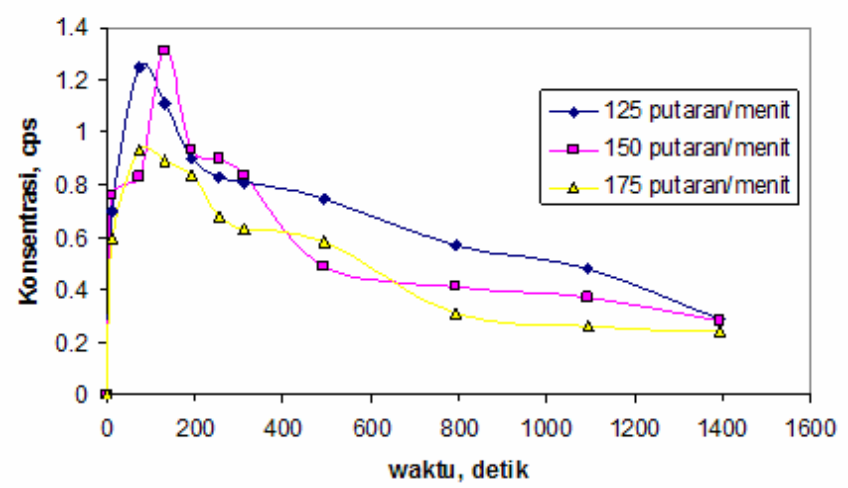

Gambar 2. Hubungan Konsentrasi Perunut Dengan Waktu Pada Kecepatan Pengaduk 125 Putaran/Detik

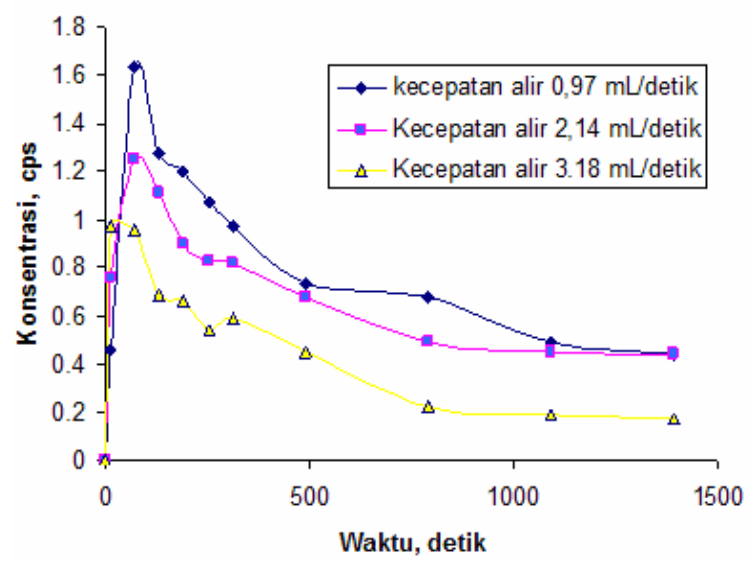

Gambar 3. Pengaruh Putaran Pengaduk

Waktu tinggal rata-rata sesungguhnya dihitung menggunakan Persamaan 5. Selanjutnya, dengan Persamaan 9 dan bantuan Persamaan 6, 7, dan 8 dengan cara Newton Raphson ${ }^{[11]}$ dapat dihitung bilangan dispersi aksial. Hasil perhitungan disajikan pada Tabel 1. untuk variasi kecepatan alir. Agar diperoleh persamaan yang dapat dipergunakan lebih luas, variasi kecepatan pengaduk diubah menjadi Bilangan Reynold, menggunakan Persamaan 11 dan hasilnya disajikan pada Tabel 2. 
Tabel 1. Perhitungan Waktu Tinggal dan D/uL pada Beberapa Kecepatan Alir (Kecepatan Pengaduk 125 Putaran/Menit)

\begin{tabular}{ccc}
\hline Kec. Alir $(\mathrm{mL} / \mathrm{s})$ & $\mathrm{t}_{\mathrm{s}}{ }^{*}$, detik & $\mathrm{D} / \mathrm{uL}$ \\
\hline 0,97 & 351 & 10,18 \\
2,14 & 339 & 11,08 \\
3,18 & 269 & 21,40 \\
\hline
\end{tabular}

Dari Tabel 1 dapat dilihat bahwa semakin besar kecepatan alir, nilai D/uL semakin besar. Hal ini menunjukkan bahwa penyebaran semakin cepat. Bilangan dispersi yang diperoleh semua di atas 0,01 yang berarti bahwa dispersi atau penyebaran partikel atau komponen-komponen dalam reaktor terjadi dengan cepat atau pencampuran bersifat ideal. Data hubungan $\mathrm{D} / \mathrm{uL}$ dengan waktu tinggal rata-rata dapat dibuat grafik yang disajikan pada Gambar 4.

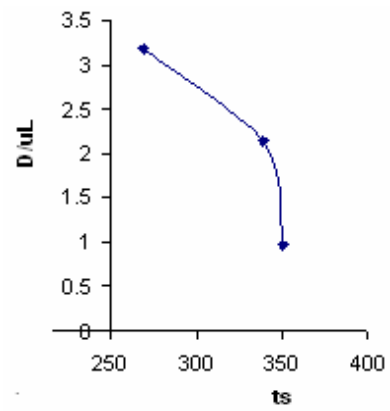

Gambar 4. Hubungan D/uL dengan ts

Dari Gambar 4 diperoleh hubungan bilangan dispersi dengan waktu tinggal rata-rata pada kisaran 269 sampai dengan 351 detik dapat ditulis dengan Persamaan 12.

$$
\mathrm{D} / \mathrm{uL}=9 \times 10^{-4}\left(\mathrm{t}_{\mathrm{s}}^{*}\right)^{2}-6,9 \times 10^{-1}\left(\mathrm{t}_{\mathrm{s}}^{*}\right)+148
$$

Persamaan 12 dapat digunakan untuk menghitung D/uL pada beberapa kecepatan alir yang dinyatakan sebagai Bilangan Reynold menurut 10. Hasilnya disajikan pada Tabel 2.

Tabel 2. Hasil Perhitungan D/uL pada Beberapa Kecepatan Alir (Kecepatan Alir, Fv = 2,14 mL/detik)

\begin{tabular}{cccc}
\hline $\begin{array}{c}\text { Kec putar pengaduk, } \\
\text { putaran/menit }\end{array}$ & Bilangan Reynold & $\mathrm{t}_{\mathrm{s}}{ }^{*}$, detik & $\mathrm{D} / \mathrm{uL}$ \\
\hline 125 & 1585 & 339 & 11,08 \\
150 & 1902 & 329 & 13,31 \\
175 & 2219 & 315 & 13,74 \\
\hline
\end{tabular}


Dari Tabel 2 dapat dilihat bahwa, semakin tinggi bilangan Reynold bilangan dispersi semakin besar. Hal ini sesuai dengan pengertian Bilangan Reynold yang menunjukkan bahwa semakin besar bilangan Reynold berarti dinamika fluida di dalam sistem semakin turbulen. Hubungan bilangan dispersi dengan Bilangan Reynod dapat dibuat grafik yang disajikan pada Gambar 5.

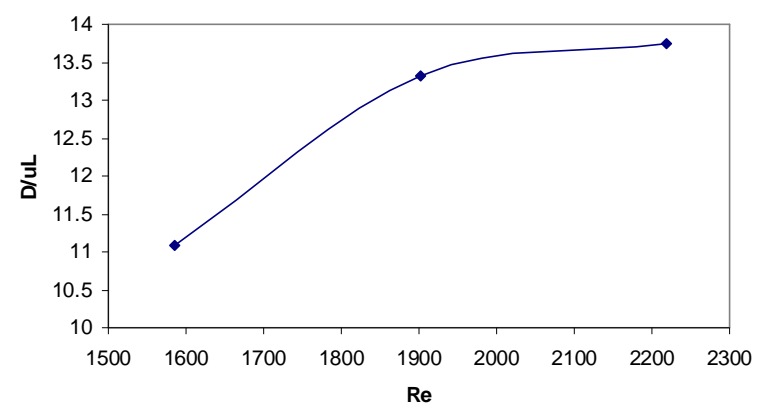

Gambar 5. Hubungan D/uL dengan Bilangan Reynold

Jika bilangan dispersi dan bilangan Reynold dibuat dalam bentuk persamaan diperoleh Persamaan 13.

$$
\mathrm{D} / \mathrm{uL}=65,7 \mathrm{e}^{0,0003 / \operatorname{Re}}
$$

Persamaan 13 diperoleh pada kisaran Bilangan Reynold 1585 sampai dengan 2215.

\section{KESIMPULAN}

Dari hasil penelitian yang diperoleh, maka dapat ditarik kesimpulan sebagai berikut:

1. Perunut radioisotop dapat digunakan untuk mengevaluasi unjuk kerja reaktor alir tangki berpengaduk dengan menentukan distribusi waktu tinggal untuk menghitung bilangan dispersi..

2. Makin besar kecepatan alir umpan bilangan dispersi semakin besar.

3. Makin besar Bilangan Reynold, semakin besar pula bilangan dispersi.

4. Bilangan dispersi reaktor yang dievaluasi berkisar antara 11,08-21,40 yang berarti bahwa pencampuran dalam reaktor bersifat sempurna atau reaktor ideal.

5. Hubungan bilangan dispersi dengan waktu tinggal rata-rata pada kisaran 269-351 detik dapat ditulis dengan persamaan $\mathrm{D} / \mathrm{uL}=9 \times 10^{-4}\left(\mathrm{t}_{\mathrm{s}}{ }^{*}\right)^{2}-$ $6,9 \times 10^{-1}\left(\mathrm{t}_{\mathrm{s}}^{*}\right)+148$

6. Hubungan bilangan dispersi dengan bilangan Reynold pada kisaran 1585-2215 dapat ditulis dengan persamaan $\mathrm{D} / \mathrm{uL}=65,7 \mathrm{e}^{0,0003 / \mathrm{Re}}$. 


\section{UCAPAN TERIMA KASIH}

Penulis mengucapkan terima kasih kepada Bapak Ir. Bangun Wasito, M.Sc. yang telah memberikan koreksi dan saran yang membangun untuk perbaikan tulisan ini.

\section{DAFTAR PUSTAKA}

1. MARKERTIHARTHA, IGBN, 2000, Teknik Reaksi Kimia, Jurusan Teknik Kimia, ITB, Bandung.

2. RASE, H.F., 1977, Chemical Reactor Design for Process Plant, Vol 1, John Wiley and Sons, New York.

3. LEVENSPIEL, O., 1999, Chemical Reaction Engineering, 3 ed., John Wiley and Sons, New York.

4. SULISTYO, H. dan HANDAYANI, W.R., 1997, "Unjuk Kerja Reaktor Alir Tangki Berpengaduk", Forum Teknik Jilid 21, Nomor 2.

5. RIDWAN, M., dkk., 1978, Pengatar Ilmu Pengetahuan dan Teknologi Nuklir, Badan Tenaga Atom Nasional, Jakarta.

6. INDROJONO dan SYALFANI, Aplikasi Isotop dan Radiasi pada Distribusi Minyak, Badan Tenaga Atom Nasional, Jakarta.

7. BABA, S., et al 1985, "Aplication of radioisotopo tracer to analytical gas chromatography B: Biomedical Science and Aplications", Volume 341, pp 251259.

8. FUMAN, Z.S.L., 2004, "Radioisotope tracer investigation and modeling of copper concentrate dewatering process", International Journal of Mineral Processing, Volume 73, Issue 1, January 2004, pages 37-43.

9. FOGLER, S, 1992, Element of Chemical Reaction Engineering, 3 ed., John Wiley and Sons, New York.

10. WANDOWO, Aplikasi Isotop dalam Industri dan Hidrologi, Badan Tenaga Atom Nasional, Jakarta.

11. SEDIAWAN, W.B., dan PRASETYO, A., 1997, Pemodelan Matematis dan Penyelesaian Numeris dalam Teknik Kimia dengan Pemrograman Bahasa Basic dan Fortran, Penerbit Andi, Yogyakarta. 
